\title{
The Overview of Spinal Cord Injury
}

\section{Gede Surya Dinata ${ }^{1}$, Anak Agung Gede Wira Pratama Yasa ${ }^{2}$}

\author{
${ }^{1}$ Prodi Kedokteran, Universitas Pendidikan Ganesha \\ ${ }^{2}$ Prodi Kedokteran, Universitas Pendidikan Ganesha
}

e-mail: surya.dinata@undiksha.ac.id, anak.agung.wira@undiksha.ac.id

\begin{abstract}
Abstrak
Spinal cord injury (SCl) atau cedera medula spinalis adalah suatu kondisi gangguan pada medula spinalis atau sumsum tulang belakang dengan gejala fungsi neurologis mulai dari fungsi motorik, sensorik, dan otonomik, yang dapat berujung menjadi kecacatan menetap hingga kematian. Gejala dapat bervariasi tergantung tingkat lokasi dan keparahan lesi cedera yang dapat berupa gejala neurologis seperti nyeri pada bagian tengah dari punggung, parasthesia, hingga penurunan kesadaran pada pasien. Mekanisme terjadinya $\mathrm{SCl}$ dapat terjadi secara langsung atau cedera primer dan apabila pasien tidak diberikan penanganan segera dan adekuat, cedera primer akan berlanjut menjadi cedera sekunder. Informasi yang didapatkan sebelum pasien masuk ke unit gawat darurat penting untuk didapatkan seperti mekanisme dari terjadinya cedera, dan penanganan pre-hospital. Penanganan pasien $\mathrm{SCI}$ dapat menggunakan teknik $\mathrm{ABCD}$ dan dapat dilakukan tindakan pembedahan darurat apabila pasien memiliki faktor risiko tertentu. Bila pasien tidak mendapat penanganan intensif dan segera, maka cedera dapat berlanjut menjadi defisit neurologis serta kecacatan yang menetap hingga akhir hayat pasien. Maka dari itu, penting bagi kita sebagai seorang klinisi untuk mengetahui dari struktur anatomi dan fisiologi medula spinalis, epidemiologi, etiologi, patogenesis, gejala klinis, diagnosis, tatalaksana, serta prognosis dari $\mathrm{SCl}$, sehingga dapat melakukan pengamatan dan penanganan awal pada pasien yang terindikasi SCI.
\end{abstract}

Kata kunci: cedera medula spinalis, epidemiologi, etiologi, diagnosis, tatalaksana

\begin{abstract}
Spinal cord injury is a condition with impairment of the spinal cord with a neurological symptomp from motor, sensory, and autonomic functions, that can lead to permanent disability and death. Symptoms can vary depending on the location and severity of the injured lesion. The mechanism of spinal cord injury can occur directly or primary injury and if the patient is not given prompt and adequate treatment, the primary injury will progress to a secondary injury. Information obtained before the patient is admitted to the emergency department is important to obtain such as the mechanism of injury, and pre-hospital management. The treatment of spinal cord injury is using the ABCD and emergency surgery can be performed if the patient has certain risk factors. If the patient does not receive intensive and prompt treatment, the injury can progress to neurological deficits and disability that persist until the end of the patient's life. Therefore, it is important for clinicians to know from the anatomical structure and physiology of the spinal cord, epidemiology, etiology, pathogenesis, clinical symptoms, diagnosis, management, and prognosis of spinal cord injury, so that early observation and treatment can be do to patients who indicated spinal cord injury.
\end{abstract}

Keywords: spinal cord injury, epidemiology, etiology, diagnose, treatment 


\section{PENDAHULUAN}

Spinal cord injury $(\mathrm{SCl})$ atau cedera medula spinalis adalah suatu kondisi gangguan pada medula spinalis atau sumsum tulang belakang dengan gejala fungsi neurologis mulai dari fungsi motorik, sensorik, dan otonomik, yang dapat berujung menjadi kecacatan menetap hingga kematian. Menurut $\mathrm{WHO}, \mathrm{SCl}$ diperkirakan terjadi sebanyak 40-80 kasus per 1 juta penduduk dalam setahun. Ini artinya terjadi sekitar $300.000-600.000$ kasus SCl yang ada di seluruh dunia setiap tahunnya. Hal ini tentunya tidak terlepas dari risiko terjadinya kejadian $\mathrm{SCl}$ yang sebagian besar disebabkan oleh karena kasus traumatik (90\%), meliputi kecelakaan lalu lintas (50\%), jatuh (25\%), olahraga atau kecelakaan akibat pekerjaan (10\%) (Pertiwi \& Berawi, 2017). Hasil studi lainnya menunjukkan bahwa lebih dari $70 \%$ pasien $\mathrm{SCl}$ juga akan mengalami beberapa cedera lainnya yang menjadi bukti bahwa kejadian SCl pada kasus traumatik yang sangat tinggi. Sehingga setiap ditemukannya kejadian trauma yang mengakibatkan cedera multipel baik dengan defisit neurologis ataupun tidak, harus dipertimbangkan adanya $\mathrm{SCl}$.

Penelitian pada negara maju menyatakan bahwa pada pasien yang menderita tetraplegia dan paraplegia memiliki tingkat harapan hidup $91,2 \%$ dan $95,9 \%$, walaupun tidak menjamin pasien dapat kembali normal secara utuh tanpa kecacatan sama sekali (Alizadeh, Dyck, \& Karimi-Abdolrezaee, 2019). Hal ini dapat terjadi karena sekitar $5 \%$ pasien masih mendapat penanganan kegawatdaruratan yang salah seperti manipulasi berlebih dan immobilisasi tulang belakang yang tidak adekuat mengakibatkan pasien mendapat gejala neurologis tambahan dan atau gejala yang semakin buruk setelah perawatan (ATLS, 2018). Selain itu, penanganan yang telat juga dapat menyebabkan risiko komplikasi dan kecacatan menetap pada pasien semakin meningkat. Melihat dari hal tersebut, tentunya kejadian $\mathrm{SCl}$ perlu menjadi perhatian bagi kita sebagai seorang klinisi untuk mengetahui epidemiologi, etiologi, faktor risiko, patofisiologi, diagnosis, dan tatalaksana sehingga menghasilkan prognosis berupa angka harapan hidup dan kualitas hidup pasien dapat semakin meningkat pada SCl.

\section{METODE}

Penulisan artikel ini bedasarkan metode literature review dari artikel penelitian terkait dengan diagnosis dan tatalaksana Cedera Medula Spinalis yang sudah terpublikasi. Artikel penelitian didapatkan bedasarkan hasil penelusuran pada platform PubMed, Science Direct, dan Google Scholar dengan memasukan kata kunci yang telah ditentukan sesuai dengan judul artikel. Artikel yang digunakan merupakan artikel yang dipublikasi dalam 10 tahun terakhir

\section{HASIL DAN PEMBAHASAN}

Medula spinalis berada didalam tulang belakang dan memiliki struktur serta jaringan kompleks yang berfungsi untuk menyalurkan informasi dan instruksi dari otak ke berbagai bagian tubuh dan sebaliknya. Struktur dari tulang belakang terdiri atas 7 tulang servikal, 12 tulang torakal, 5 tulang lumbar, 5 tulang sacrum, 5 tulang coccygea. Setiap tulang belakang akan mengalirkan sejumlah serabut saraf yang berfungsi secara neurologis yang mengatur dalam setiap fungsi sensorik dan motorik sesuai dengan dermatom yang dapat dilihat pada (Gambar 1). Sekitar 55\% kejadian SCI terjadi pada bagian servikal dan diikuti oleh torakal (15\%), torakolumbal (15\%), dan lumbosakral (15\%) (ATLS, 2018). Menurut penelitian sekitar $80 \%$ pasien $\mathrm{SCl}$ yang mengenai bagian servikal, sebagian besar akan meninggal di tempat. Selain karena tingkat lesi cedera yang tinggi, bagian servikal memiliki mobilitas dan tingkat eksposur yang tinggi sehingga terjadinya distrupsi pada organ pasien akan semakin mudah. SCI bagian torakal lebih jarang terjadi karena adanya mobilitas yang lebih sederhana dan terlindungi oleh tulang rusuk, namun kasus ini tidak dapat dikesampingkan karena pasien dapat menderita kesulit bernapas akibat paralisis dari otot interkosta dan atau diafragma. 


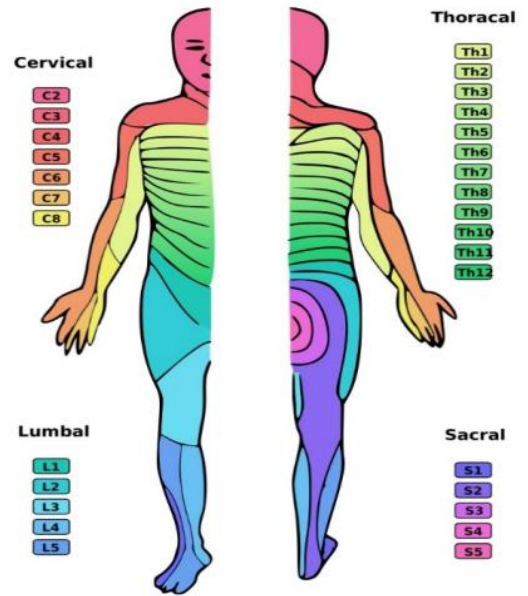

Gambar 1. Dermatom pada manusia (Whitman PA, 2020)

Kebanyakan pasien yang menderita SCI merupakan laki-laki usia remaja dewasa muda dengan kasus utama oleh karena kecelakaan lalu lintas. Namun, dari hasil penelitian yang diadakan di negara jepang ditemukan juga kasus dari kelompok lansia yang saat ini mengalami peningkatan populasi dengan rata-rata sebagian besar kasus lansia mengalami $\mathrm{SCl}$ yang disebabkan oleh karena jatuh $(41 \%)$ dengan usia rata-rata 50-59 tahun. Hal ini juga tidak terlepas dari penyakit degeneratif dan juga kongenital yang menyebabkan pengapuran pada bagian servikal dari tulang belakang sehingga menjadikan kelompok usia lansia menjadi rentan terkena cedera tulang belakang (Copley et al., 2020).

Etiologi dari SCI secara garis besar, $\mathrm{SCl}$ dapat dibedakan menjadi 2 yaitu traumatik dan non-traumatik. Kasus traumatik memiliki tingkat kejadian yang lebih banyak (90\%) ketimbang nontraumatik (10\%) dengan kasus traumatik paling sering antara lain kecelakaan lalu lintas, diikuti oleh jatuh, olahraga atau kecelakaan akibat pekerjaan dan rekreasi, serta kekerasan (Christopher, Witiw, \& Fehlings, 2015; Pertiwi \& Berawi, 2017).

Kecelakaan lalu lintas terutama kendaraan bermotor paling sering terjadi pada sebagian besar wilayah di seluruh dunia. Letak geografis seperti dataran tinggi diperkirakan menjadi penyebab utama kasus kecelakaan (Christopher et

langsung dapat terjadi karena adanya transmisi kinetik lewat jaringan saraf, tanpa al., 2015). Selanjutnya, Jatuh dari ketinggian merupakan kasus traumatik paling umum kedua setelah kecelakaan lalu lintas. Di negara maju, hal ini dapat terjadi oleh karena faktor degenerasi dari kelompok lansia usia 60 tahun yang saat ini populasinya sedang meningkat, sehingga biasanya terjadi secara low fall (jatuh dengan ketinggian < 1 meter). Sedangkan pada negara berkembang, tingkat kejadian akibat jatuh biasanya disebabkan oleh karena jatuh dari ketinggian atau high fall, yang menjadi cerminan konstruksi di negara berkembang yang masih belum merata dalam memenuhi standar keamanan (Christopher et al., 2015).

Degenerative Cervical Myelopathy (DCM) merupakan SCl non-traumatis paling umum ditemukan yang disebabkan oleh penyakit degeneratif progresif dari kompresi pada tulang belakang secara kronis, yang ditandai dengan tonjolan pada diskus intervertebralis posterior dan hipertrofi atau invaginasi ligamen flavum, yang disertai dengan kerusakan medula spinalis bagian servikal. Penyakit ini sering asimptomatik, dengan onset bulan hingga tahun, dengan ditemukannya mielopati pada serviks oleh proses degenerasi yang mengakibatkan penurunan fungsi motorik dan sensorik (David et al., 2019).

Mekanisme dari bagaimana terjadinya $\mathrm{SCl}$ dapat terjadi bedasarkan onsetnya menjadi 2 yaitu cedera primer dan cedera sekunder. Cedera primer merupakan cedera awal yang bersifat akut dan tiba-tiba, disebabkan oleh faktor mekanis seperti kasus traumatis yang memiliki gaya tekan dan transformasi energi tinggi, sehingga akan menyebabkan kegagalan struktur integritas biomekanis dari tulang belakang (Copley et al., 2020; Patek \& Stewart, 2020).

Cedera primer dapat terjadi secara direk maupun indirek (Copley et al., 2020). Cedera direk atau langsung disebabkan oleh karena gangguan kompresi medula spinalis transien dan persisten, distraksi, laserasi akibat akselerasi-deselerasi dan transeksi, yang akan mengakibatkan gangguan integritas struktur pendukung seperti ligamen dan tulang. Sedangkan cedera indirek atau tidak

adanya kerusakan struktur seperti fraktur. Contohnya ialah cedera hiperekstensi 
pada cervical central cord syndrome yang terjadi pada pasien lansia saat terjatuh (Copley et al., 2020). Menurut (Alizadeh et al., 2019; Patek \& Stewart, 2020), cedera primer memiliki empat mekanisme utama antara lain:

1) gangguan kompresi medula spinalis transien (sementara)

2) gangguan kompresi medula spinalis persisten atau terus menerus

3) cedera distraksi

4) laserasi atau transeksi langsung Cedera sekunder merupakan cedera lanjutan yang disebabkan oleh eksaserbasi atau lanjutan dari cedera primer. Hasil dari cedera primer seperti inflamasi dan edema lokal atau sistemik, hipotensi, hipoksemia, serta perdarahan, memicu dari patofisiologi cascade yang akan menghasilkan gangguan perfusi dan pengiriman oksigen serta aliran darah kedalam bagian medula spinalis yang sedang mengalami kerusakan (Christopher et al., 2015; Copley et al., 2020; Patek \& Stewart, 2020). Menurut (Ahmed \& Lucas, 2020; Christopher et al., 2015; Copley et al., 2020), cedera sekunder dapat dibagi menjadi beberapa fase yaitu fase segera ( $<2$ jam), fase awal akut ( $<48$ jam), dan fase sub akut $(<2$ minggu) dengan tanda dan gejala pada yang dapat dilihat pada (Tabel 1).

\begin{tabular}{|c|c|c|}
\hline Segera & Awal Akut & Subakut \\
\hline Perdarahan & Iskemia & $\begin{array}{l}\text { Infiltrasi } \\
\text { makrofag }\end{array}$ \\
\hline $\begin{array}{l}\text { Nekrosis } \\
\text { seluler }\end{array}$ & $\begin{array}{l}\text { Peningkatan } \\
\text { edema }\end{array}$ & $\begin{array}{l}\text { Astrosito- } \\
\text { sis reaktif }\end{array}$ \\
\hline $\begin{array}{l}\text { Pelepasan } \\
\text { glutamat }\end{array}$ & $\begin{array}{l}\text { Produksi } \\
\text { radikal bebas }\end{array}$ & \\
\hline Peningkata & Disregulasi ion & \\
\hline n regulasi & Eksositosis & \\
\hline & glutaminergik & \\
\hline & imunologis & \\
\hline
\end{tabular}

Tabel 1. Fase cedera sekunder

bedasarkan onset (Christopher et al., 2015; Copley et al., 2020)

Fase ini dapat berlanjut menjadi fase intermediet atau fase menengah, dimana terjadi gliosis yang berkembang dalam kurun waktu kurang dari 6 bulan yang menyebabkan timbulnya jaringan parut pada akson (Copley et al., 2020). Dalam waktu lebih dari 6 bulan, fase intermediet akan berkembang menjadi fase kronis yang menyebabkan pembentukan dari syringomyelia atau kista pada tulang belakang yang saat ini masih dilakukan penelitian lebih lanjut mengenai pembentukan tersebut (Ahmed \& Lucas, 2020; Copley et al., 2020).

Gejala klinis yang timbul bervariasi seperti nyeri, paralisis, paresis, inkontinensia, tergantung dari 2 faktor yaitu bedasarkan tingkat keparahan dari SCI dan bedasarkan letak dari cedera di sepanjang medula spinalis (Eckert \& Martin, 2017; Pertiwi \& Berawi, 2017). Bedasarkan tingkat keparahannya, SCI dapat dibagi menjadi 2 yaitu cedera komplit dan inkomplit. Cedera komplit dan inkomplit dapat dibedakan lewat karakteristiknya yang dapat dilihat pada (Tabel 2) (Pertiwi \& Berawi, 2017).

\begin{tabular}{|c|c|c|}
\hline $\begin{array}{l}\text { Karakter- } \\
\text { istik }\end{array}$ & Lesi komplit & $\begin{array}{l}\text { Lesi } \\
\text { inkomplit }\end{array}$ \\
\hline Motorik & $\begin{array}{l}\text { (-) disepanjang } \\
\text { bagian bawah } \\
\text { lesi }\end{array}$ & Sering $(+)$ \\
\hline Protopatik & $\begin{array}{l}\text { (-) disepanjang } \\
\text { bagian bawah } \\
\text { lesi }\end{array}$ & Sering $(+)$ \\
\hline $\begin{array}{l}\text { Propio- } \\
\text { septik }\end{array}$ & $\begin{array}{l}\text { (-) disepanjang } \\
\text { bagian bawah } \\
\text { lesi }\end{array}$ & Sering $(+)$ \\
\hline $\begin{array}{l}\text { Sacral } \\
\text { sparing }\end{array}$ & Negatif & Positif \\
\hline $\begin{array}{l}\text { Radiologi } \\
\text { vertebra }\end{array}$ & $\begin{array}{l}\text { Fraktur, luksasi, } \\
\text { listesis }\end{array}$ & normal \\
\hline $\mathrm{MRI}$ & $\begin{array}{l}\text { Perdarahan } \\
\text { (sering), } \\
\text { kompresi, } \\
\text { kontusio }\end{array}$ & $\begin{array}{l}\text { Edema } \\
\text { (sering), } \\
\text { kontusio, } \\
\text { normal }\end{array}$ \\
\hline
\end{tabular}


Ganesha Medicina Journal, Vol 1 No 2 September 2021

\begin{tabular}{|c|c|c|c|c|}
\hline Karakteristik & $\begin{array}{l}\text { Central cord } \\
\text { syndrome }\end{array}$ & $\begin{array}{c}\text { Brown sequard } \\
\text { syndrome }\end{array}$ & $\begin{array}{l}\text { Anterior } \\
\text { cord } \\
\text { syndrome }\end{array}$ & $\begin{array}{l}\text { Posterior } \\
\text { cord } \\
\text { syndrome }\end{array}$ \\
\hline Kejadian & Sering & Jarang & Jarang & $\begin{array}{l}\text { Sangat } \\
\text { jarang }\end{array}$ \\
\hline $\begin{array}{c}\text { Biomekanis } \\
\text { Motorik }\end{array}$ & $\begin{array}{l}\text { Hiperekstensi } \\
\text { Bervariasi, } \\
\text { paralisis } \\
\text { komplit } \\
\text { jarang }\end{array}$ & $\begin{array}{l}\text { penetrasi } \\
\text { Paresis } \\
\text { ipsilateral }\end{array}$ & $\begin{array}{l}\text { hiperfleksi } \\
\text { Paralisis } \\
\text { komplit } \\
\text { bilateral }\end{array}$ & $\begin{array}{c}\text { Hiperekstensi } \\
\text { Bervariasi }\end{array}$ \\
\hline Protopatik & $\begin{array}{c}\text { Bervariasi } \\
\text { dan tidak } \\
\text { khas }\end{array}$ & $\begin{array}{l}\text { Kontralateral } \\
\text { hilang total }\end{array}$ & $\begin{array}{l}\text { Hilang } \\
\text { total, } \\
\text { bilateral } \\
\text { utuh }\end{array}$ & $\begin{array}{c}\text { Bervariasi, } \\
\text { biasanya } \\
\text { ringan }\end{array}$ \\
\hline Proprioseptik & $\begin{array}{c}\text { Jarang } \\
\text { gangguan }\end{array}$ & $\begin{array}{c}\text { Ipsilateral hilang } \\
\text { total }\end{array}$ & Utuh & terganggu \\
\hline Perbaikan & $\begin{array}{l}\text { Nyata dan } \\
\text { cepat }\end{array}$ & $\begin{array}{c}\text { fungsi buruk } \\
\text { pada ipsilateral, } \\
\text { independensi } \\
\text { baik }\end{array}$ & $\begin{array}{l}\text { Paling } \\
\text { buruk }\end{array}$ & nyata \\
\hline
\end{tabular}

Tabel 3. Jenis Spinal cord syndrome (Pertiwi \& Berawi, 2017)

Cedera komplit adalah cedera dengan keadaan gangguan kegagalan fungsi neurologis secara absolut dimana pasien tidak dapat merasakan sensasi dan maupun menggerakan fungsi motorik dibawah tingkat cedera pada tulang belakang (Eckert \& Martin, 2017; Pertiwi \& Berawi, 2017). Sedangkan cedera inkomplit adalah cedera dengan penurunan fungsi neurologis baik sensorik dan motorik dibawah bagian dari cedera tulang belakang sehingga tidak dapat melakukan fungsi maksimal, biasanya masih dapat berfungsi utuh hingga sedikit namun tidak sampai gagal fungsi (Eckert \& Martin, 2017; Pertiwi \& Berawi, 2017). Walaupun memiliki gejala dan prognosis lebih baik daripada cedera komplit, cedera inkomplit dapat menyebabkan berbagai gejala neurologis yang disebut spinal cord syndrome. Spinal cord syndrome sering kali tidak terdeteksi ataupun salah terdiagnosis pada saat pemeriksaan neurologis karena memiliki gejala yang bervariasi tergantung letak dan tingkat keparahannya (Tabel 3) (Gambar 3) (Copley et al., 2020; Pertiwi \& Berawi, 2017).

Bedasarkan letak cedera SCI yang digolongkan bedasarkan letak cedera akan menghasilkan gejala neurologis yang bervariasi (Tabel 4) yang dapat ditentukan melalui pengukuran dan penilaian fungsi neurologis baik motorik dan sensorik disepanjang tulang belakang pasien. Pemeriksaan akan dilakukan menggunakan tusuk jarum atau pin prick test dan sensasi sentuhan untuk mengukur respon sensorik yang disesuaikan dengan dermatom.

\begin{tabular}{|c|c|}
\hline $\begin{array}{l}\text { Tingkat } \\
\text { Cedera }\end{array}$ & Gangguan yang berpotensi \\
\hline C2-C3 & $\begin{array}{l}\text { Bersifat fatal, adanya } \\
\text { kerusakan pada } \\
\text { pernapasan diafragma }\end{array}$ \\
\hline C4 & $\begin{array}{lr}\text { Kuadriplegia } & \text { dengan } \\
\text { gangguan saraf diafragma } \\
\text { dan otot dinding dada yang } \\
\text { menyebabkan } \\
\text { bernapas }\end{array}$ \\
\hline C5 & $\begin{array}{l}\text { Kuadriparesis dengan } \\
\text { gangguan fungsi pada bahu } \\
\text { dan siku yang disertai } \\
\text { gangguan saraf diafragma } \\
\text { dan otot dinding dada yang }\end{array}$ \\
\hline & $\begin{array}{l}\text { menyebabkan sulit } \\
\text { bernapas }\end{array}$ \\
\hline C6 & $\begin{array}{l}\text { Kuadriparesis dengan } \\
\text { gangguan fungsi pada } \\
\text { bahu, siku, pergelangan } \\
\text { tangan yang disertai } \\
\text { gangguan saraf diafragma } \\
\text { dan otot dinding dada yang }\end{array}$ \\
\hline & $\begin{array}{l}\text { menyebabkan sulit } \\
\text { bernapas }\end{array}$ \\
\hline
\end{tabular}




\begin{tabular}{|c|c|}
\hline C7 & $\begin{array}{l}\text { Kuadriparesis dengan } \\
\text { gangguan fungsi pada } \\
\text { bahu, siku, pergelangan } \\
\text { tangan, dan fungsi tangan- } \\
\text { jari yang buruk (hanya dapat } \\
\text { ekstensi jari) }\end{array}$ \\
\hline C8 & $\begin{array}{l}\text { Kuadriparesis dengan } \\
\text { lengan berfungsi normal } \\
\text { namun pada carpal lemah }\end{array}$ \\
\hline T1-T6 & $\begin{array}{l}\text { Paraplegia dengan fungsi } \\
\text { bagian bawah dada tengah } \\
\text { hilang namun masih dapat } \\
\text { mengontrol lengan }\end{array}$ \\
\hline T7-T12 & $\begin{array}{l}\text { Paraplegia dengan fungsi } \\
\text { pada pinggang kebawah } \\
\text { hilang dan gangguan } \\
\text { kontrol pada trunkus }\end{array}$ \\
\hline L1-S5 & $\begin{array}{l}\text { Paraparesis pada otot kaki } \\
\text { tergantung tingkatan }\end{array}$ \\
\hline
\end{tabular}

Tabel 4. Gangguan neurologis bedasarkan tingkat cedera pada tulang belakang (Copley et al., 2020)

Dalam melakukan penegakkan diagnosis terhadap kasus trauma medula spinalis, tentunya harus didahului oleh melakukan initial assesment and resucitation sebelum melakukan serangkaian pemeriksaan penunjang yang bertujuan untuk menegakkan diagnosis ataupun mengeleminasi dari diagnosis kerja. The American Spinal cord injury Association (ASIA) Scoring saat ini menjadi sebuah aspek skoring yang sering digunakan dan merupakan standar internasional dalam melakukan pengkajian terhadap tingkat keparahan dan klasifikasi SCI (Gambar 2) (Eckert \& Martin, 2017).

Penilaian melalui skoring ini dimulai pemeriksaan dari bagian paling distal otot ke proksimal (termasuk pemeriksaan light touch, pin prick test, dan rectal toucher) yang sesuai dengan dermatome dan idealnya selesai dalam 72 jam pasca cedera (Copley et al., 2020; Eckert \& Martin, 2017). Nilai yang didapat bedasarkan seberapa besar sensasi yang bisa pasien rasakan di beberapa titik tubuh (sensorik) dan tes fungsi motorik. Setelah pemeriksaan akan ditentukan penggolongan pasien sesuai dengan gangguan bedasarkan grade (kelas) yang dimulai dari grade $\mathrm{E}$ dimana fungsi neurologis pasien normal hingga grade $A$ (fungsi motorik dan sensorik hilang lebih dari 3 tingkat dibawah lesi cedera (termasuk daerah dubur) (Copley et al., 2020).

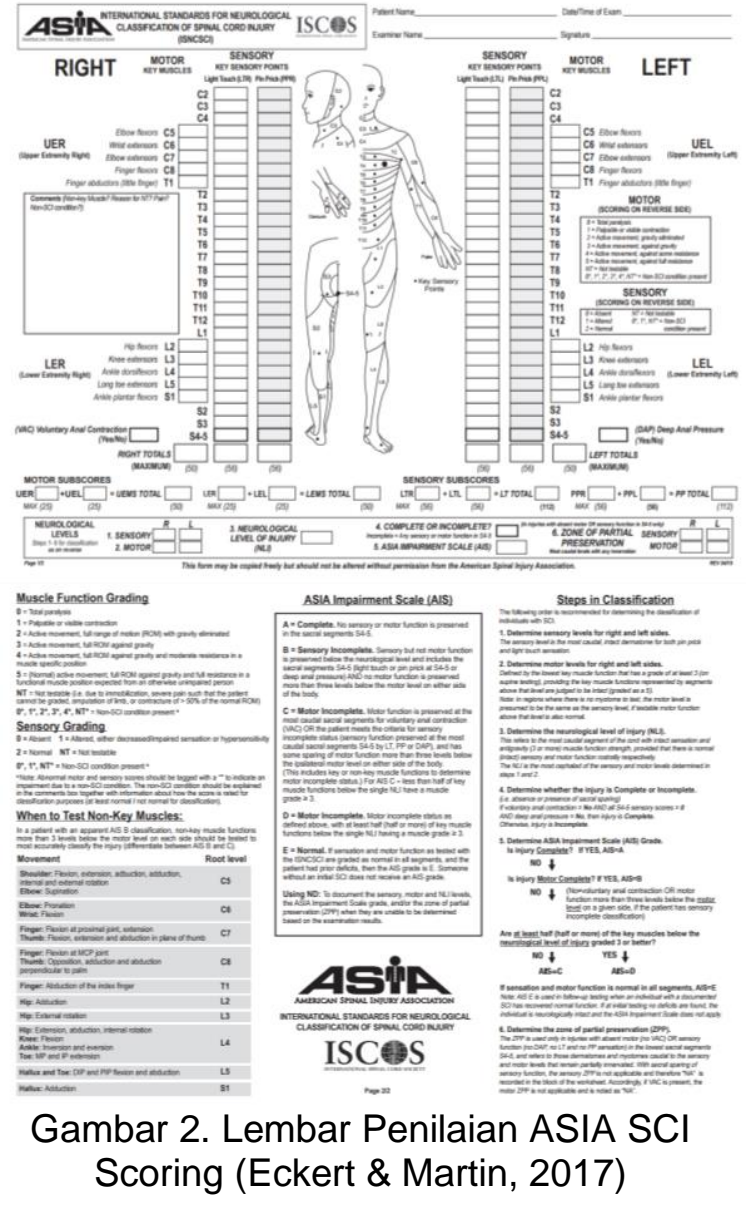

Setiap pasien yang mengalami kasus traumatik dengan indikasi tertentu akan mendapatkan perlindungan dengan CCollar yang digunakan pada leher atau servikal pasien pada saat pengaktifan emegercency medical service (EMS). Setelah pasien dilakukan penilaian dan resusitasi awal, kuisioner Canadian $C$ Spine Rule (CCR) (Gambar 3) dan the National Emergency X-Radiography Utilization Study (NEXUS) akan berperan dalam menentukan apakah pasien dapat melepaskan C-Collar atau pasien memerlukan pemeriksaan pencitraan lebih lanjut.

Pada sebuah penelitian yang dilakukan oleh (Souter, K.H. \& J., 2017) dalam mengukur tingkat temuan klinis menggunakan penilaian NEXUS memiliki tingkat akurasi 99,8\% sehingga pemeriksaan ini menjadi standar dalam 
melakukan pengangkatan C-Collar pada pasien yang normal, dan perujukan untuk mengambil gambaran radiologis apabila pasien memenuhi salah satu dari kriteria sebagai berikut:

1) Ada defisit neurologis dari riwayat dan pemeriksaan fisik

2) Terdapat gejala intoksikasi etoh (alkohol)

3) Riwayat cedera distraksi ektrem

4) Tingkat kesadaran menurun $(\mathrm{GCS}<15)$

5) Tenderness pada tulang belakang

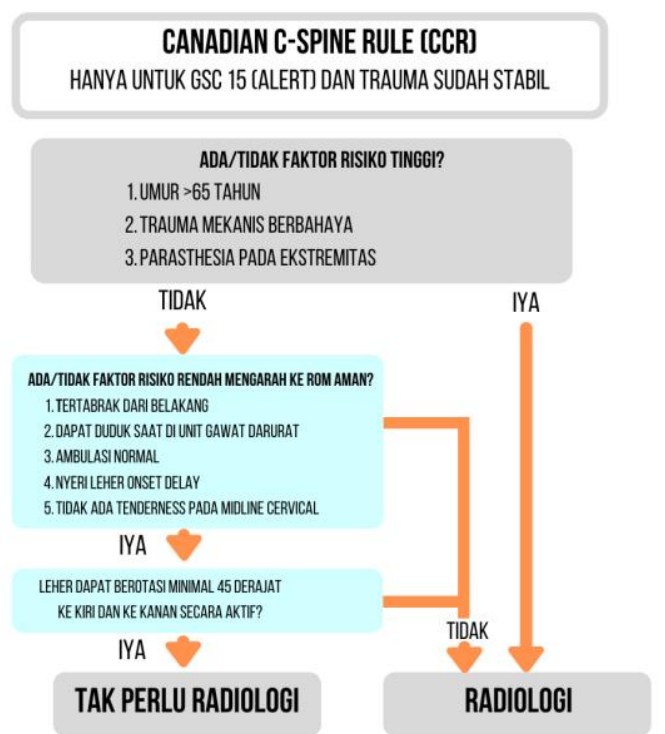

Gambar 3. Canadian C-Spine Rule guidelines (ATLS, 2018)

Pemeriksaan diagnostik berupa pencitraan dapat dilakukan setelah pasien mendapat penilaian dan resusitasi awal serta jika pasien memenuhi kriteria pada kuisioner CCR dan NEXUS. Tes pencitraan yang dapat dilakukan dapat berupa X-ray, Computerized Tomography (CT) Scan, dan Magnetic Resonance Imaging (MRI). CT-scan saat ini direkomendasikan dalam melakukan evaluasi dan memberikan hasil mendetail terkait jenis dan lokasi tulang belakang dalam struktur anatomi. Pada pasien dalam keadaan tidak sadar atau mengalami trauma multipel disarankan untuk melakukan pemeriksaan CT pada area kepala, leher, dada, perut, dan panggul dengan view koronal dan sagital (Souter, K.H. \& J., 2017).

Meski begitu terdapat kekurangan dari CT-scan yang masih belum dapat melihat struktur jaringan lunak lebih jauh seperti sumsum tulang, ligamen, intervertebralis disk, dan paraspinal sehingga diperlukan pemeriksaan MRI untuk melihat struktur tersebut apabila pasien mengalami defisit neurologis tanpa temuan apapun pada X-ray dan CT Scan (Copley et al., 2020; Souter, K.H. \& J., 2017). Penilaian imaging dilakukan untuk memberikan informasi tambahan terkait indikasi pasien dalam melakukan pembedahan lebih lanjut. Terdapat berbagai macam cara dalam mengambil gambar pada pemeriksaan pencitraan tergantung letak dan lokasi cedera pada trauma medula spinalis (Gambar 4) (Copley et al., 2020).
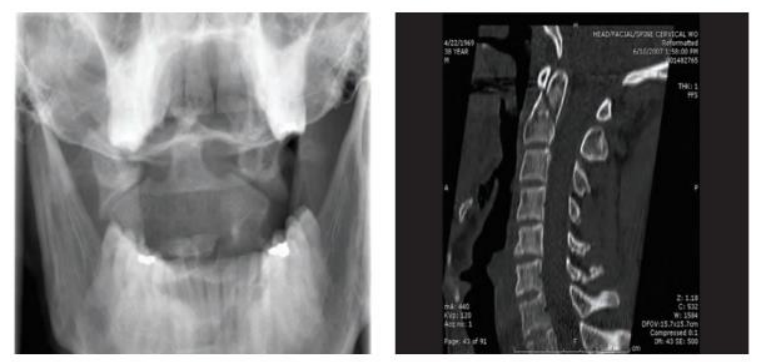

Gambar 4. Hasil pencitraan fraktur pada bagian servikal medula spinalis, hasil pemeriksaan X-ray pada pasien dengan fraktur jefferson (disrupsi fraktur anterior dan posterior $\mathrm{C} 1$ dengan pergeseran di lateral) dan hasil pemeriksaan CT-Scan pada pasien dengan fraktur odontoid (fraktur pada bagian basal dens) (ATLS, 2018).

Tujuan utama dalam melakukan penatalaksanaan trauma medula spinalis akut adalah melakukan terapi yang menyebabkan SCI primer dan mencegah cedera lanjutan atau sekunder pada $\mathrm{SCl}$ dengan pelaksanaan A (airway), B (breathing), C (circulation), D (disability), E (exposure) jika pasien dalam kondisi gawat darurat. Bila ditemukan pasien mengalami nyeri pada bagian punggung tengah, sulit berbicara, penurunan kesadaran, motorik dan sensorik pada ekstremitas, maka patut dicurigai pasien menderita trauma medula spinalis (Sjamsuhidajat \& Jong, 2019; Souter, K.H. \& J., 2017). Informasi pada pre-hospital merupakan hal yang krusial untuk diketahui mulai dari informasi 
mengenai mekanisme cedera teruama pada pasien yang memiliki gangguan neurologis seperti penurunan kesadaran dan defisit sensorik berupa paralisis atau parasthesia serta pasien yang memiliki trauma multipel. Tentunya, apabila pasien mengalami cedera multipel wajib halnya melakukan pengamatan dan mendahulukan penanganan terhadap tanda dan gejala lain dari pasien yang mengancam jiwa seperti airway, pneumothoraks, hemothoraks, perdarahan berat (Souter, K.H. \& J., 2017). Diperlukan mobilisasi yang minimal saat pelaksanaan survei primer pada pasien dengan menggunakan C-Collar pada leher, blok, dan tape (pita perekat), serta penggunaan manuver log rolling, dan backboard sebagai tempat pasien (Copley et al., 2020; Souter, K.H. \& J., 2017). Bila tidak memiliki peralatan C-Collar maka diusahakan kepala pasien menghadap ke depan dan tetap ditengah dengan penambahan penyangga leher berupa bantal atau gulungan kain agar tulang belakang tetap intak saat pengangkutan (Sjamsuhidajat \& Jong, 2019).

$$
\text { Dalam manajemen }
$$

Airway, memberikan oksigenasi yang adekuat sangatlah penting untuk mencegah dari iskemia dan cedera sekunder medula spinalis. Pasien yang memiliki gejala pada pernapasan seperti sesak, takipnea, sulit berbicara, ataupun penurunan kesadaran dapat dilakukan penilaian awal terhadap pernapasan baik patensi jalan napas dan oksigenasi yang adekuat (Patek \& Stewart, 2020). Pemeriksaan airway umumnya dilakukan manuver "head tilt - chin lift - jaw thrust" pada pasien yang mengalami penurunan kesadaran, namun manuver ini tidak direkomendasikan pada pasien yang suspek trauma medula spinalis yang memerlukan pembatasan manipulasi. Saat ini manuver yang direkomendasikan pada pasien suspek trauma medula spinalis yaitu "jaw thrust - open mouth".

Penanganan terhadap jalan napas biasanya dilakukan pada pasien dengan berbagai penyebab seperti obstruksi akibat benda asing, darah, ataupun muntahan pasien. Pada pasien yang mengalami cedera pada servikal pada kasus traumatik kemungkinan dapat menyebabkan distrupsi pada laring dan trakea ataupun perdarahan pada jaringan, yang menyebabkan obstruksi jalan napas parsial, dan perlu dilakukan pemberian terapi airway definitif segera (ATLS, 2018). Penanganan dapat berupa obat-obatan ataupun peralatan patensi jalur napas dengan teknik yang sudah familiar dilakukan oleh klinisi. Kerja sama tim dalam penanganan ini merupakan kunci utama, dimana dalam penanganan patensi jalan napas dapat membutuhkan minimal 2 orang untuk melakukan serangkaian tindakan anastesi, intubasi, dan menjaga tulang belakang tetap immobilisasi (Patek \& Stewart, 2020).

Dalam manajemen breathing, pasien yang mengalami SCI pada bagian servikal hingga toraks terutama diatas T8, biasanya memiliki gangguan pada fungsi otot diafragma dan atau interkorta yang akan menyebabkan kegagalan napas sehingga diperlukan tindakan supportif berupa pemberian ventilasi napas. Pasien dengan ancaman gagal napas dapat dilakukan penatalaksanaan berupa intubasi endotrakeal tube dan ventilator mekanik (Souter, K.H. \& J., 2017). Kesulitan dalam melakukan pemasangan ventilator pada pasien dengan $\mathrm{SCl}$ sering ditemukan terutama pada pasien yang mengalami SCl lengkap pada servikal, sehingga penanganan dengan trakeostomi direkomendasikan (Copley et al., 2020). Pasien yang memiliki lesi komplit pada C2 keatas memerlukan ventilator jangka panjang. Pada pasien yang memiliki lesi pada C3-C5 yang memiliki inervasi ke diafragma langsung memiliki tindakan yang bervariasi namun memerlukan intubasi segera. Lesi pada C5 kebawah dipertimbangkan pemberian ventilator jangka panjang oleh karena otot interkosta yang dapat berpotensi memunculkan spasme otot.

Dalam manajemen circulation, The American Society of Anesthesiologists merekomendasikan monitoring tandatanda vital pasien dengan SCl seperti denyut jantung, elektrokardiogram, tekanan darah, oksimetri nadi, kapnografi, dan suhu. Pasien yang mengalami SCl traumatik umumnya mengalami perdarahan hebat yang dapat berujung pada keadaan syok hipovolemik yang akan menyebabkan hipotensi (SBP $<90 \mathrm{mmHg}$ ). 
Pada kondisi ini, pasien memerlukan pemberian cairan segera untuk resusitasi agar kembali menjadi euvolemik (Souter, K.H. \& J., 2017). Namun, pada kondisi tertentu, pasien yang sudah diberikan cairan namun masih tetap hipotensi, dapat dicurigai pasien menderita syok neurogenik.

Syok neurogenik biasanya terjadi pada pasien yang mengalami $\mathrm{SCl}$ diatas T6 yang akan menyebabkan vasodilatasi, bradikardi, dan hipotensi serta dapat terjadi bradikardia berat atau asistol saat dilakukan tatalaksana yang menstimulasi refleks vagal seperti laringoskopi atau suctioning (Patek \& Stewart, 2020; Souter, K.H. \& J., 2017). Penanganan pada pasien syok neurogenik memerlukan obat-obatan vasopressor seperti Noradrenalin, fenilefrin, atau metaraminol, dan dopamin inotropik positif direkomentasikan untuk menangani tonus vaskular yang mencegah cedera sekunder (Patek \& Stewart, 2020; Souter, K.H. \& J., 2017). Direkomendasikan melakukan monitoring terhadap tekanan darah menggunakan arterial line dan kateter vena sentral untuk melakukan pemberian obat sekaligus monitoring tekanan vena sentral (Patek \& Stewart, 2020).

Dalam manajemen disability, pemeriksaan neurologis lengkap harus segera dilakukan dan dapat dilakukan secara simultan dengan pemeriksaan lainnya untuk menilai tingkat lokasi dan keparahan defisit neurologis. Pemantauan terhadap pemeriksaan neurologis dapat dinilai menggunakan American Spinal Injury Association Spinal cord injury (ASIA $\mathrm{SCl}$ ) scoring (Gambar 4) yang dapat melihat fungsi neurologis motorik dan sensorik pasien secara menyeluruh. Pemeriksaan lainnya yang dapat dilakukan berupa pemeriksaan punggung dan rectal toucher yang dilakukan setelah pasien terlepas dari log roll untuk meminimalisir dari mobilisasi (Patek \& Stewart, 2020; Souter, K.H. \& J., 2017). Pemeriksaan lanjutan yang diberikan ialah penilaian menggunakan assesment kuisioner seperti NEXUS dan CRR untuk mengevaluasi apakah pasien perlu tindakan lanjutan dengan melakukan pemeriksaan radiodiagnostik atau tidak.
Setelah pasien stabil pasca resusitasi $A B C D$, maka tahapan selanjutnya yaitu melakukan terapi lanjutan. Tujuan dari terapi lanjutan yakni mencegah lesi transversa, mempercepat resolusi dan revalidasi, rehabilitasi aktif, serta mempermudah dan mempercepat dalam proses perawatan dan fisioterapi secara aktif (Patek \& Stewart, 2020; Sjamsuhidajat \& Jong, 2019). Tindakan lanjutan yang dapat dilakukan yaitu pembedahan dan atau farmakologi dengan pertimbangan dari pemeriksaan radiodiagnostik dan sejumlah kuisioner lainnya yang mengindikasikan apakah pasien perlu dilakukan tindakan bedah atau hanya konservatif (Copley et al., 2020). Namun, tidak menutup kemungkinan untuk dilakukannya tindakan pembedahan darurat pada pasien dengan kondisi-kondisi tertentu seperti (1) pasien yang mengalami luka tembus oleh karena peluru, penikaman, dan senjata tajam, (2) acute spinal cord syndrome, (3) gangguan neurologis progresif akibat penekanan. Pembedahan yang dapat dilakukan berupa reposisi dan stabilisasi jika mengalami dislokasi, dan dekompresi pada pasien yang mengalami tanda-tanda kompresi medula spinalis akibat deformitas, fragmen tuang, hematoma, dan perlukaan (Sjamsuhidajat \& Jong, 2019).

Farmakologi pada pasien trauma medula spinalis masih menjadi sebuah perdebatan hingga saat ini. Farmakologi yang saat ini menjadi rekomendasi yaitu kortikosteroid jenis metilprednisolon dengan dosis $30 \mathrm{mg} / \mathrm{kgBB}$ bolus IV yang berguna dalam mencegah terjadinya inflamasi dan menekan migrasi netrofil serta meningkatkan permeabilitas vaskular (Pertiwi \& Berawi, 2017). Menurut hasil penelitian yang dilakukan oleh Surgical Timing in Acute Spinal cord injury Study (STASCIS), menunjukkan bahwa pasien yang diberikan metilprednisolon dalam kurun waktu <24 jam setelah cedera dapat menurunkan komplikasi lanjutan dibanding dengan pasien yang tidak diberikan terapi kortikosteroid sama sekali (Copley et al., 2020). Pemberian dosis tinggi metilprednisolon direkomendasikan pada pasien $<8$ jam setelah cedera pertama dan tidak direkomendasikan untuk melakukan pemberian metilprednisolon dalam kurun 
waktu 48 jam karena dapat menyebabkan efek samping lebih lanjut (Copley et al., 2020). Bila diberikan dalam kurun waktu $<3$ jam setelah cedera, terapi dapat dilanjutkan selama 23 jam dengan metilprednisolon IV kontinyu dosis $5,4 \mathrm{mg} / \mathrm{kgBB} / \mathrm{jam}$. Terapi ini efektif dalam meningkatkan fungsi motorik dan sensorik baik pada cedera parsial maupun total dengan masing-masing dalam kurun waktu pemberian terapi 6 minggu dan 6 bulan (Pertiwi \& Berawi, 2017). Namun menurut (Eckert \& Martin, 2017; Patek \& Stewart, 2020) menyebutkan bahwa terapi farmakologi jenis steroid tidak direkomendasikan setelah dilakukannya uji coba oleh National Acute Spinal cord injury Studies (NASCIS) yang mengalami kegagalan terhadap perbaikan fungsi neurologis sensorik dan motorik setelah 13 kali percobaan pemberian metilprednisolon dosis tinggi. Selain itu metilprednisolon juga dapat meningkatkan risiko dari sejumlah komplikasi diantaranya infeksi pada luka, pneumonia, dan sepsis.

Terapi lainnya dilakukan pada spinal cord syndrome yang memiliki tanda dan gejala yang bervariasi sehingga sering salah diagnosis saat dilakukannya pemeriksaan neurologis menyeluruh, sehingga diperlukan pengetahuan terhadap spinal cord syndrome yang dapat dilihat pada (Eckert \& Martin, 2017).

Prognosis dapat bervariasi tergantung pada tingkat, komplit tidaknya lesi, cedera yang menyertai, penyakit komorbid, dan umur dari pasien. Walaupun saat ini sudah terdapat berbagai macam peralatan canggih dan sumber daya manusia yang memumpuni, umur pasien pasca SCl umumnya lebih pendek daripada masyarakat pada umumnya dengan mortalitas sebesar 3,8\%. Rata-rata pasien akan memiliki angka harapan hidup sebesar 18,1-88,4\% (Copley et al., 2020).

$\mathrm{SCl}$ komplit umumnya memiliki yang prognosis buruk, apabila tidak mengalami perbaikan dalam 72 jam pertama akan mengalami defisit neurologi dan atau kecacatan yang menetap. Menurut penelitian, hanya sekitar $5 \%$ pasien yang berhasil mengalami perbaikan fungsi neurologis kembali normal (Pertiwi \& Berawi, 2017). Menurut (Christopher et al., 2015), hanya sekitar 10-15\% pasien dengan cedera komplit yang akan menjadi inkomplit setelah mendapatkan penanganan. SCI inkomplit memiliki prognosis yang lebih baik bedasarkan hasil penelitian dengan kemungkinan $>50 \%$ pasien dapat berjalan normal bila masih terdapat fungsi sensorik dibawah lesi (Pertiwi \& Berawi, 2017).

Bagaimana pun juga, dalam meningkatkan kualitas hidup dari pasien diperlukan dukungan secara penuh baik dari dalam diri pasien maupun lingkungan sekitar seperti dukungan dari keluarga dan sosial, kesehatan mental, kemampuan ambulasi, peluang dalam mendapat pekerjaan, dll. Sejauh ini kualitas hidup dari pasien yang terlapor cenderung meningkat dari waktu ke waktu setelah mereka beradaptasi terhadap keadaan (Copley et al., 2020).

\section{KESIMPULAN}

SCI merupakan ancaman serius yang dapat menyebabkan defisit neurologis dan kecacatan menetap pasca cedera. Kasus traumatis menjadi faktor tersering penyebab $\mathrm{SCl}$ mulai dari kecelakaan lalu lintas, jatuh, kecelakaan karena rekreasi, pekerjaan, dsb. Maka, setiap terjadinya kecelakaan dengan trauma multiple perlu dicurigai pasien menderita SCl.

Pengamatan dan penanganan dini menjadi kunci utama dalam mencegah dari cedera sekunder ataupun komplikasi lainnya yang ditimbulkan setelah cedera. Maka dari itu, penting untuk mengetahui informasi pasien pada pre-hospital seperti mekanisme terjadinya cedera, sudah tidaknya pasien diresusitasi, apakah pasien sudah dilakukan immobilisasi dengan C-Collar, dan menggunakan papan keras (backboard) dalam melakukan mobilisasi.

Penanganan dengan tindakan ABCDE pada primary survey wajib dilakukan dengan segera setelah pasien sampai di unit gawat darurat dan tindakan pembedahan darurat mungkin dilakukan pada kondisi tertentu. Prognosis pada lesi komplit umumnya buruk dan lesi inkomplit memiliki prognosis yang lebih baik. Peningkatan kualitas hidup pasca cedera merupakan hal yang krusial dialami pasien karena harus beradaptasi dengan situasi 
kecacatan pasca cedera, sehingga membutuhkan dukungan baik secara fisik, mental, dan sosial dari dalam diri pasien maupun pihak lainnya di lingkungan pasien.

\section{DAFTAR PUSTAKA}

Ahmed, A. I., \& Lucas, J. D. (2020). Spinal cord injury: pathophysiology and strategies for regeneration. Orthopaedics and Trauma, 34(5), https://doi.org/10.1016/j.mporth.2020. 06.003

Alizadeh, A., Dyck, S. M., \& KarimiAbdolrezaee, S. (2019). Traumatic spinal cord injury: An overview of pathophysiology, models and acute injury mechanisms. Frontiers in Neurology, 10(March), 1-25. https://doi.org/10.3389/fneur.2019.00 282

ATLS. (2018). Advanced trauma life support. Anaesthesia (Vol. 48). https://doi.org/10.1111/j.13652044.1993.tb07025.x

Attal, N. (2020). Spinal cord injury pain. Revue Neurologique, 0-6. https://doi.org/10.1016/j.neurol.2020. 07.003

Christopher, D., Witiw, \& Fehlings, michael g. (2015). Acute spinal cord injury. Spinal Disord Tech, 28(6), 202-210. https://doi.org/10.1002/97811191294 $00 . \operatorname{ch} 23$

Copley, P. C., Jamjoom, A. A. B., \& Khan, S. (2020). The management of traumatic spinal cord injuries in adults: a review. Orthopaedics and Trauma, 34(5), 255-265. https://doi.org/10.1016/j.mporth.2020. 06.002

Darwish, S., Tsirikos, A. I., \& Maguire, S. (2020). Rehabilitation following spinal cord injury. Orthopaedics and Trauma, 34(5), 315-319. https://doi.org/10.1016/j.mporth.2020. 06.009

David, G., Mohammadi, S., Martin, A. R., Cohen-Adad, J., Weiskopf, N., Thompson, A., \& Freund, P. (2019). Traumatic and nontraumatic spinal cord injury: pathological insights from neuroimaging. Nature Reviews Neurology, 15(12), 718-731. https://doi.org/10.1038/s41582-019-
0270-5

Eckert, M. J., \& Martin, M. J. (2017). Trauma: Spinal cord injury. Surgical Clinics of North America, 97(5), 10311045.

https://doi.org/10.1016/j.suc.2017.06. 008

Patek, M., \& Stewart, M. (2020). Spinal cord injury. Anaesthesia and Intensive Care Medicine, 21(8), 411-416. https://doi.org/10.1016/j.mpaic.2020. 05.006

Pertiwi, G. M. D., \& Berawi, K. (2017). Diagnosis dan Tatalaksana Trauma Medula Spinalis Diagnosis and Management of Spinal cord injury. Medical Proffession Journal of Lampung, 7(2), 48-52.

Sjamsuhidajat, R., \& Jong, D. (2019). Buku Ajar IImu Bedah Ed 4, Vol 3. jakarta

Souter, K.H., K. L., \& J., M. (2017). Spinal cord injury. Challenging Topics in Neuroanesthesia and Neurocritical Care, 1-339. https://doi.org/10.1007/978-3-31941445-4

Whitman PA, A. (2020). Anatomy, Skin, Dermatomes 